\title{
THE WSRC ENGINEERING ANALYZER (U)
}

by

R. R. Beckmeyer and M. R. Buckner

Westinghouse Savannah River Company

Savannah River Site

Aiken, South Carolina 29808

The information contained in this abstract was developed during the course of work done under Contract No. DE-AC09-89SR 18035 with the U.S. Department of Energy. By acceptance of this paper the publisher and/or recipient acknowledges the U.S. Government's right to retain a nonexclusive, royalty-free license in and to any copyright covering this paper, along with the right to reproduce and to authorize others to reproduce all or part of the copyrighted paper.

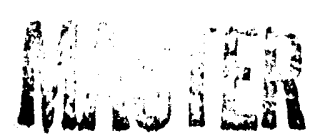




\section{DISCLAIMER}

This report was prepared as an account of work sponsored by an agency of the United States Government. Neither the United States Government nor any agency thereof, nor any of their employees, makes any warranty, express or implied, or assumes any legal liability or responsibility for the accuracy, completeness, or usefulness of any information, apparatus, product, or process disclosed, or represents that its use would not infringe privately owned rights. Reference herein to any specific commercial product, process, or service by trade name, trademark, manufacturer, or otherwise does not necessarily constitute or imply its endorsement, recommendation, or favoring by the United States Government or any agency thereof. The views and opinions of authors expressed herein do not necessarily state or reflect those of the United States Government or any agency thereof.

This report has been reproduced directly from the best available copy.

Available to DOE and DOE contractors from the Office of Scientific and Technical Information, P.O. Box 62, Oak Ridge, TN 37831; prices available from (615) 576-8401, FTS 626-8401.

Available to the public from the National Technical Information Service, U.S. Department of Commerce, 5285 Port Royal Rd., Springfield, VA 22161. 


\section{The WSRC Engineering Analyzer}

A multi-platform, multi-program engineering analysis tool that runs in either real-time or post-process modes, providing the analyst with a consistent, adaptable interface for 2 -d color animation of time-oriented engineering data on any X-terminal.

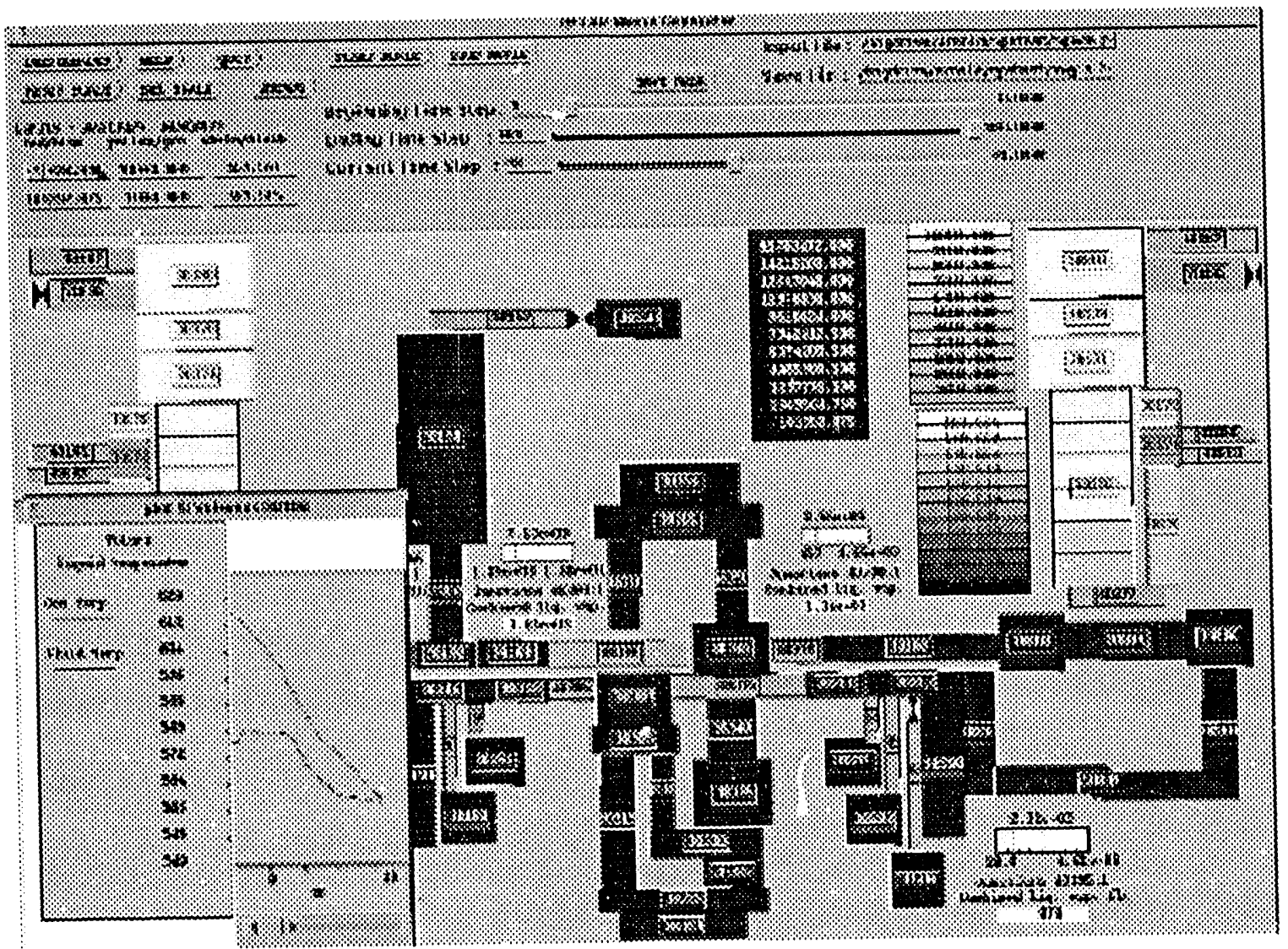

Multi-platform,

Multi-program,

Real-time,

Distributed Visualization

Engineering Analyzer
(SUN, CRAY, RS6000)

(RELAP, TRAC, user's C or FORTRAN program)

(batch, on-the-fly, and "simulation" modes)

(X-based graphics)

(2-d color animation plus trendline plots of all program output data) 


\section{The WSRC Engineering Analyzer}

Multi-platform, Multi-program, Real-time Distributed Visualization

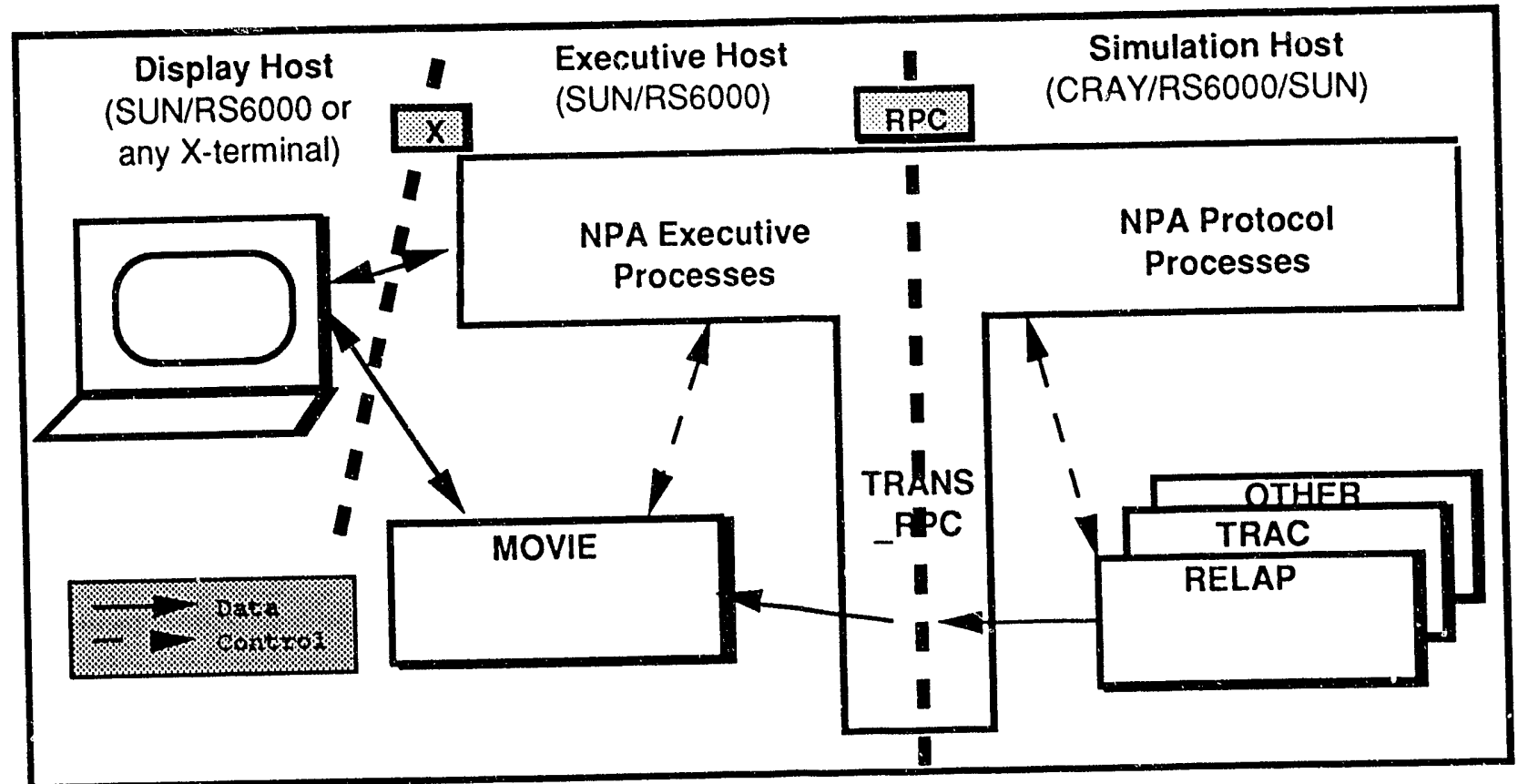

The WSRC Engineering Analyzer consists of a number of components that can be mixed and matched in a variety of ways:

MOVIE - An X-based graphical 2-d color visualization 1001 that runs in post-process and/or "real-time" mode, with trend plots available for detailed work.

TRANS_RPC - RELAP and TRAC filters that translate and transmit the complete relap.plt and trcgrf files via RPC from SUN, RS6000 and CRAY platforms to SUN and/or RS6000 platforms

TRPCLIB - FORTRAN and C libraries that can be linked to arbitrary user programs to produce data compaiible with TRANS_RPC for either batch or "real-time" processing.

EXEC/PROTOCOL - execution-time access to the model data internal to the running TRAC/RELAP or user code, in conjunction with real-time data display. 


\section{CONFIGURATIONS}

The WSRC Enginecring Analyzer can be used in the following configurations:

Post-processing - files created by TRAC and RELAP without modification to the TRAC/RELAP programs. The data being processed can either reside on the graphics host or on the computer that hosts TRAC/RELAP. In the latter configuration, the data are piped through the client/server filters as though they were produced in real-time mode.

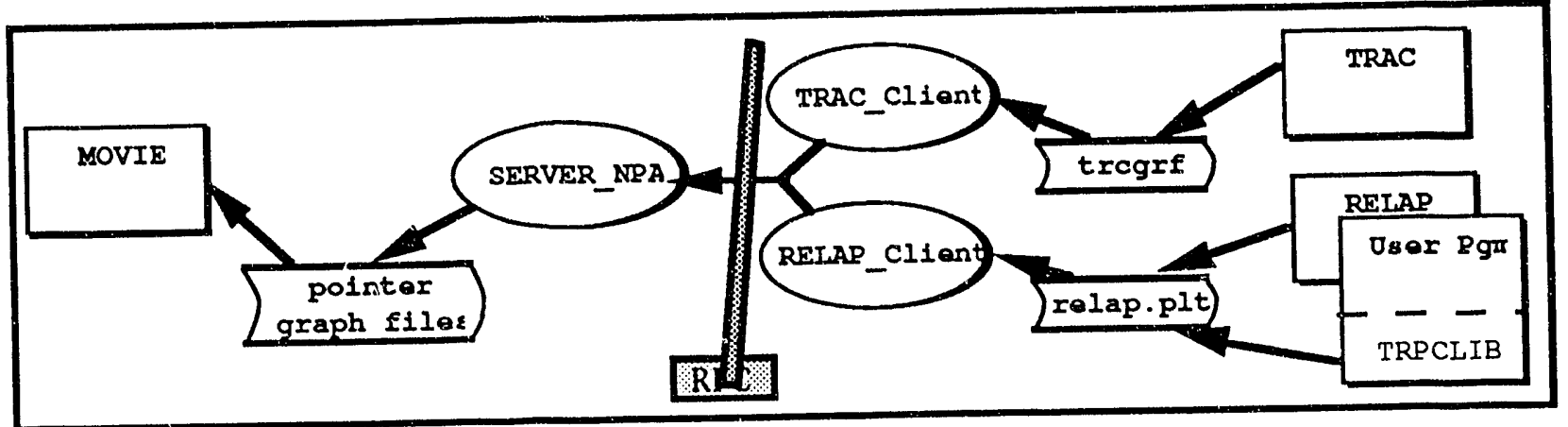

Real-time processing - the output of unmodified TRAC or RELAP, or TRPCLIBmodified arbitrary time-based simulation programs. The data are acquired, translated, and transmitted to the graphical host, where the user runs MOVIE in dynamic mode to display the data.

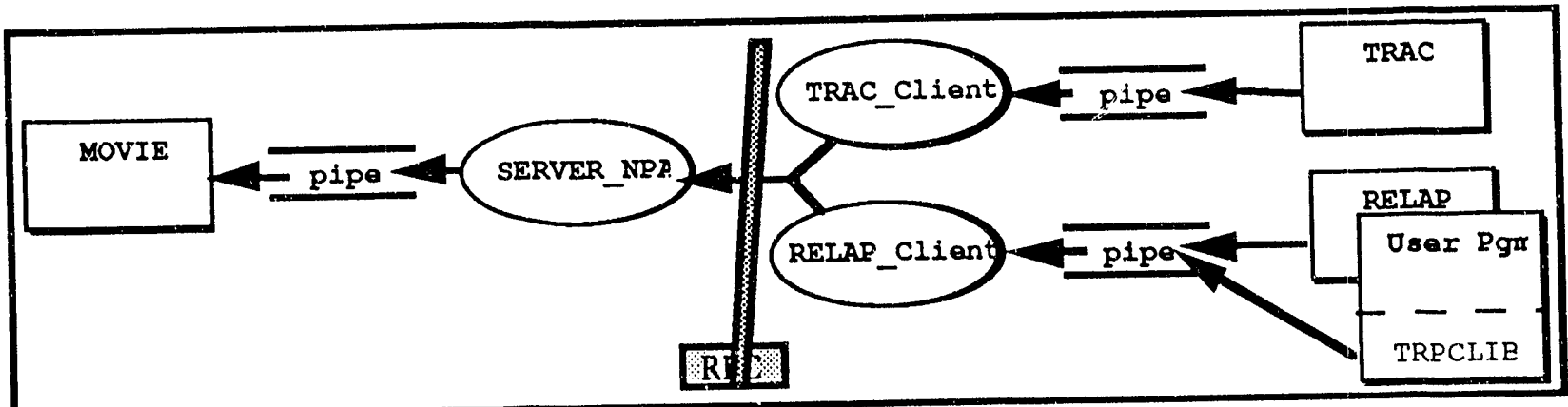




\section{CONFIGURATIONS (cont)}

Pseudo Real-time - data batch processed by the TRAC, RELAP, or other engineering program are stored on the host where they were created, but piped to MOVIE as though being produced on the fly. This mode is useful for testing, and for memory-limited executive (graphics) hosts.

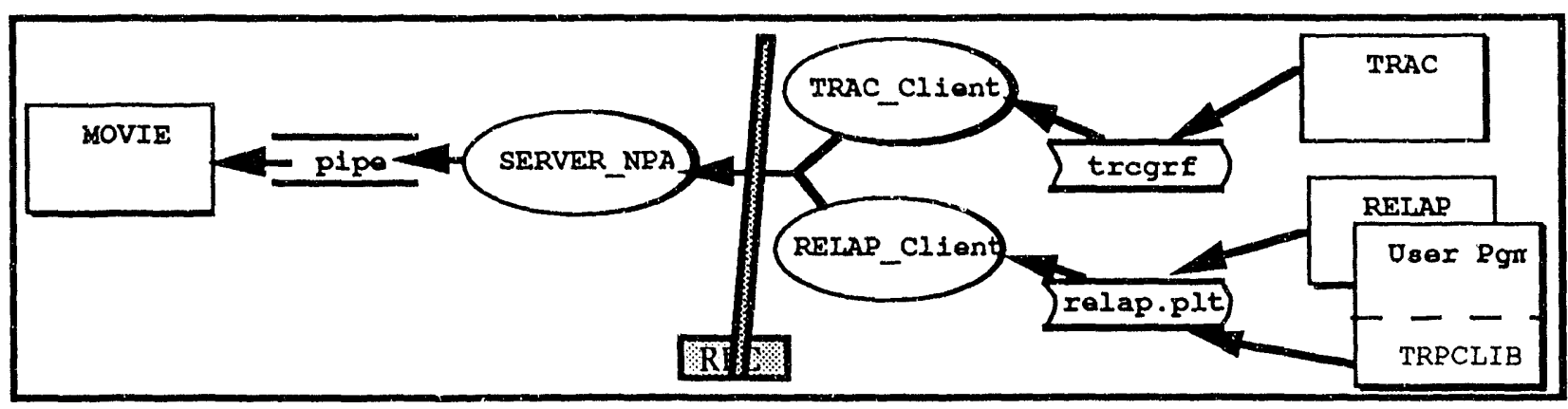

Simulator mode - real-time processing with additional synchronization, control and access software to allow model data internal to the application (RELAP, TRAC, whatever) to be set and/or displayed during the program execution.

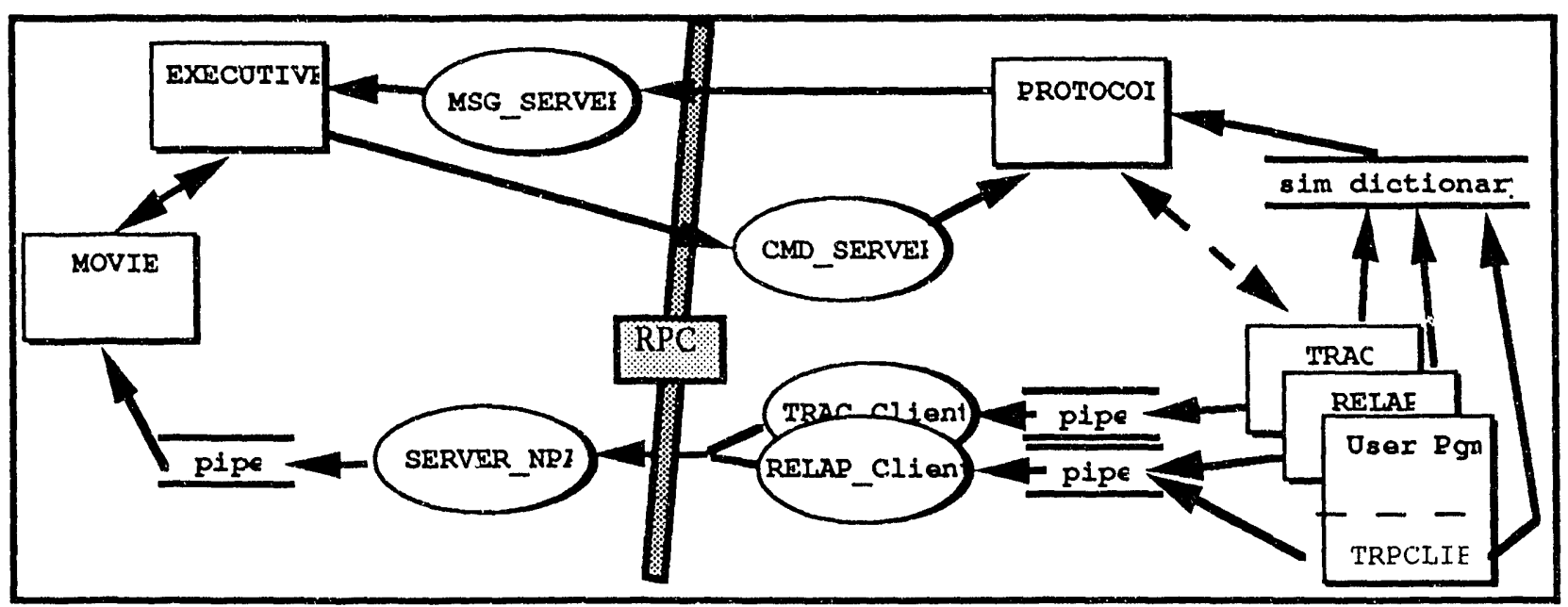




\section{PLATFORMS AND WINDOW MANAGERS}

MOVIE displays under the OPEN-LOOK, MOTIF, and MacX window managers.

The Engineering Analysis software currently runs on the following platforms:

MOVIE , EXECUTIVE - SUN and RS6000

TRANS_RPC, PROTOCOL, \& TRPCLIB - CRAY, SUN, RS6000

\section{TECHNOLOGY}

At heart, the WSRC Engineering Analyzer consists of three sets of client/server processes that together enable distributed coarse-grain multi-processing between UNIX workstations. Because the graphics is $\mathrm{X}$-based, it can be displayed on the user's $\mathrm{X}$ terminal anywhere on the site network.

The technology is available to users with various requirements:

For those users with other time-oriented $C$ or FORTRAN programs who have access to the source code, the TRPCLIB routines can be included to attach their programs to the distributed visualization tools TRANS_RPC and MOVIE.

For those users with executable versions of TRAC and/or RELAP, the TRANS_RPC filters and MOVIE can be used in post-process and real-time modes. 


\section{ATTACHMENTS}

Attached are six color screen-images of MOVIE and three papers discussing the WSRC Engineering Analyzer technology.

Screen-images:

TRAC - test loop $\mathrm{w} /$ test section in downflow boiling : void fraction per blue/yellow scale.

TRAC - Westinghouse PWR ( comp 19 is pressurizer, comp 26 is vessel, comps 2 \& 11 are steam generators) at steady state : liquid temperature per navy blue/red scale.

RELAP - Westinghouse PWR ( comp 30335 is core, comp 30150, is pressurizer, comp 30356 is upper head) during small LOCA : mixing cup quality per navy blue/red scale.

RELAP - Production Reactor Process Water System.

Third-party - Air-Water Pipe Simulation ( node 30002 closed at top, node 30006 open at bottom, nodes 30001 \& $30007=$ air at one atmosphere) : trends show water in 5 pipe nodes, node 30006 exit water flow, corresponding air counterflows.

MELCOR - Production Reactor Assembly Fluid Channels : trend shows solid temperature at one elevation in one assembly.

\section{Papers:}

"A Distributed UNIX-Based Simulator" P.W. Wyatt, T. R. Arnold, K. E. Hammer, J. S. Perry, \& G. A. McKaskle. WSRC-MS-90-141 Rev1.

"Client/Server Models for Transparent, Distributed Computational Resources" K. E. Hammer \& T. L. Gilman. WSRC-MS-90-347.

"Distributed Visualization" T. R. Arnold. WSRC-1S-91-305. 


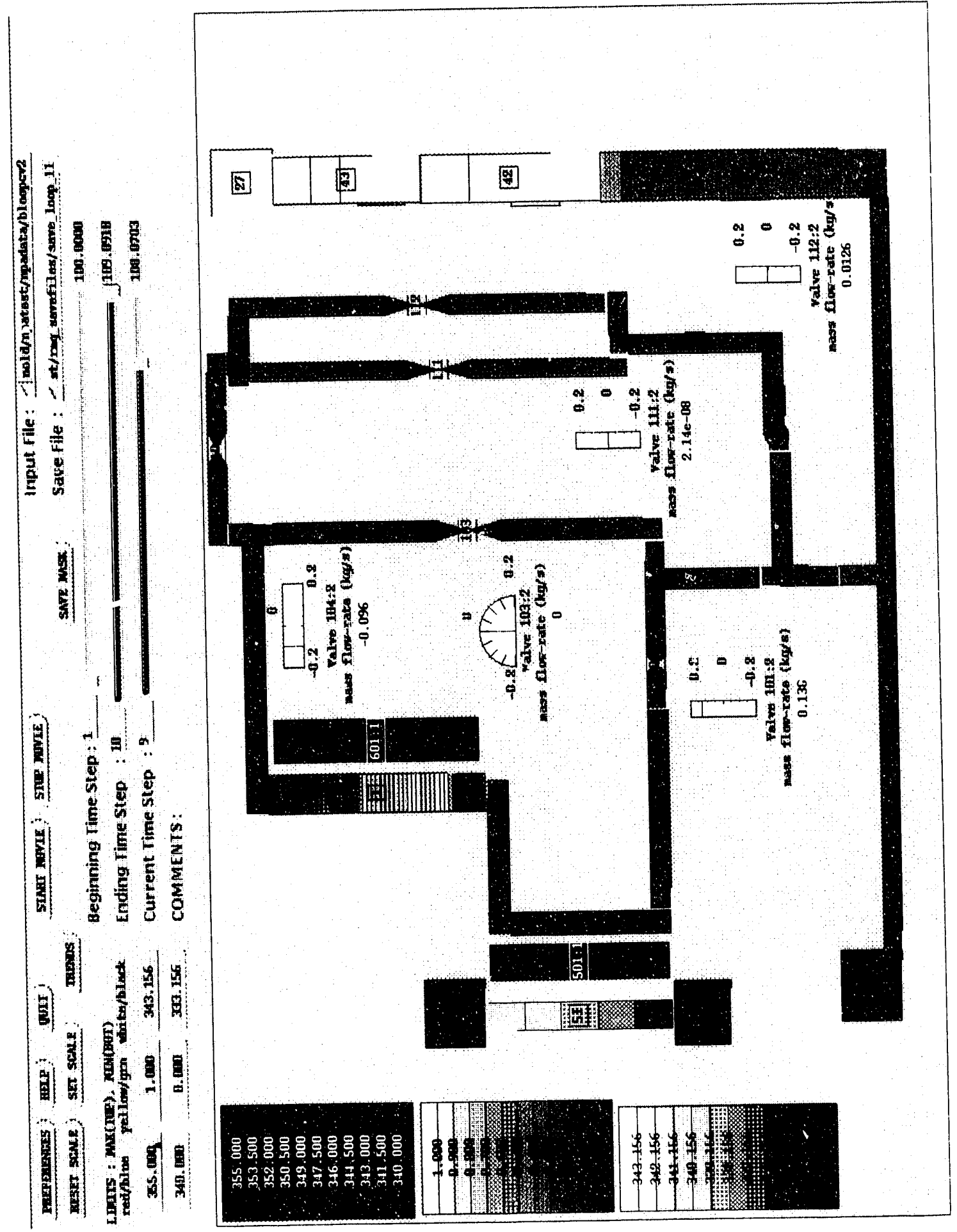




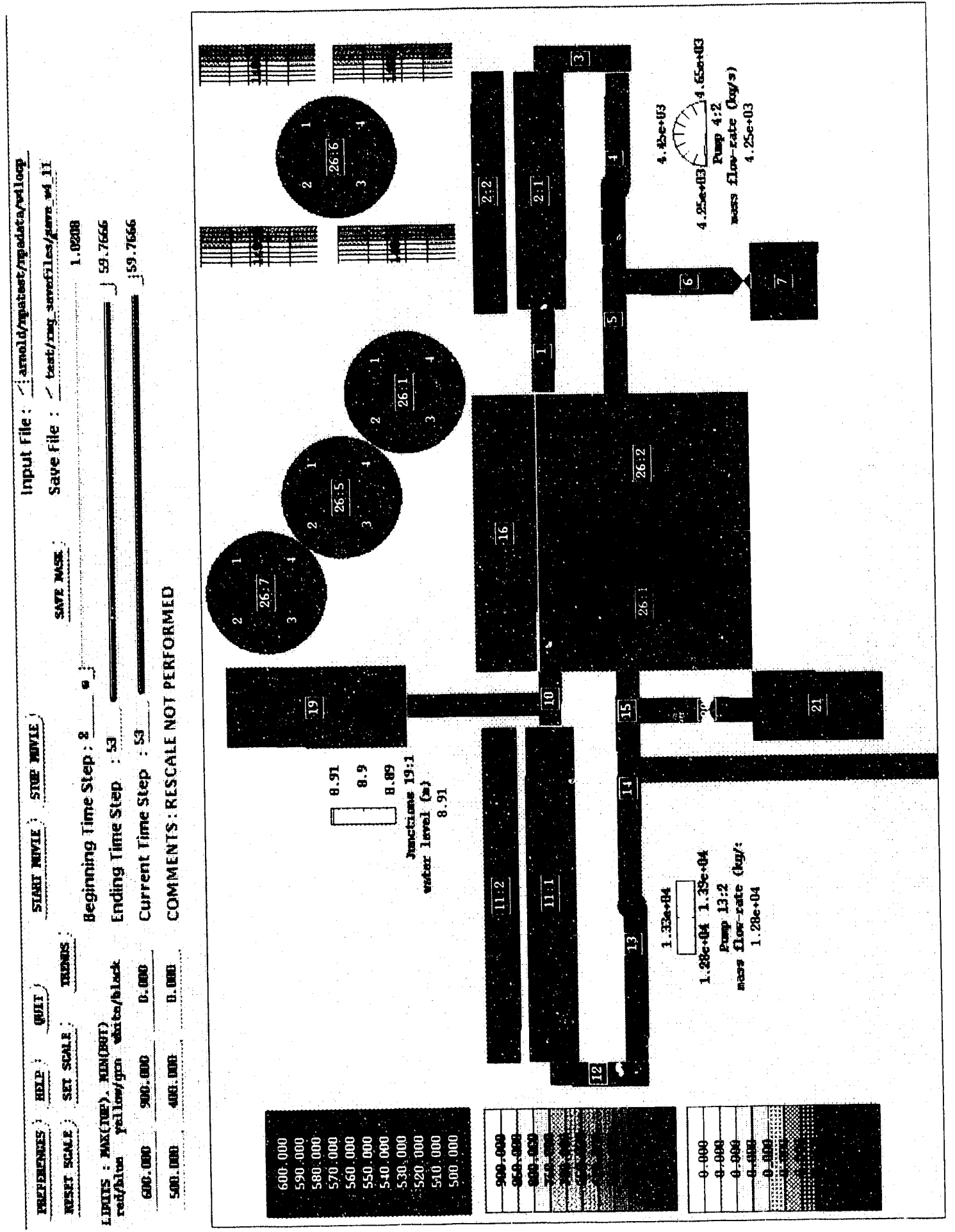




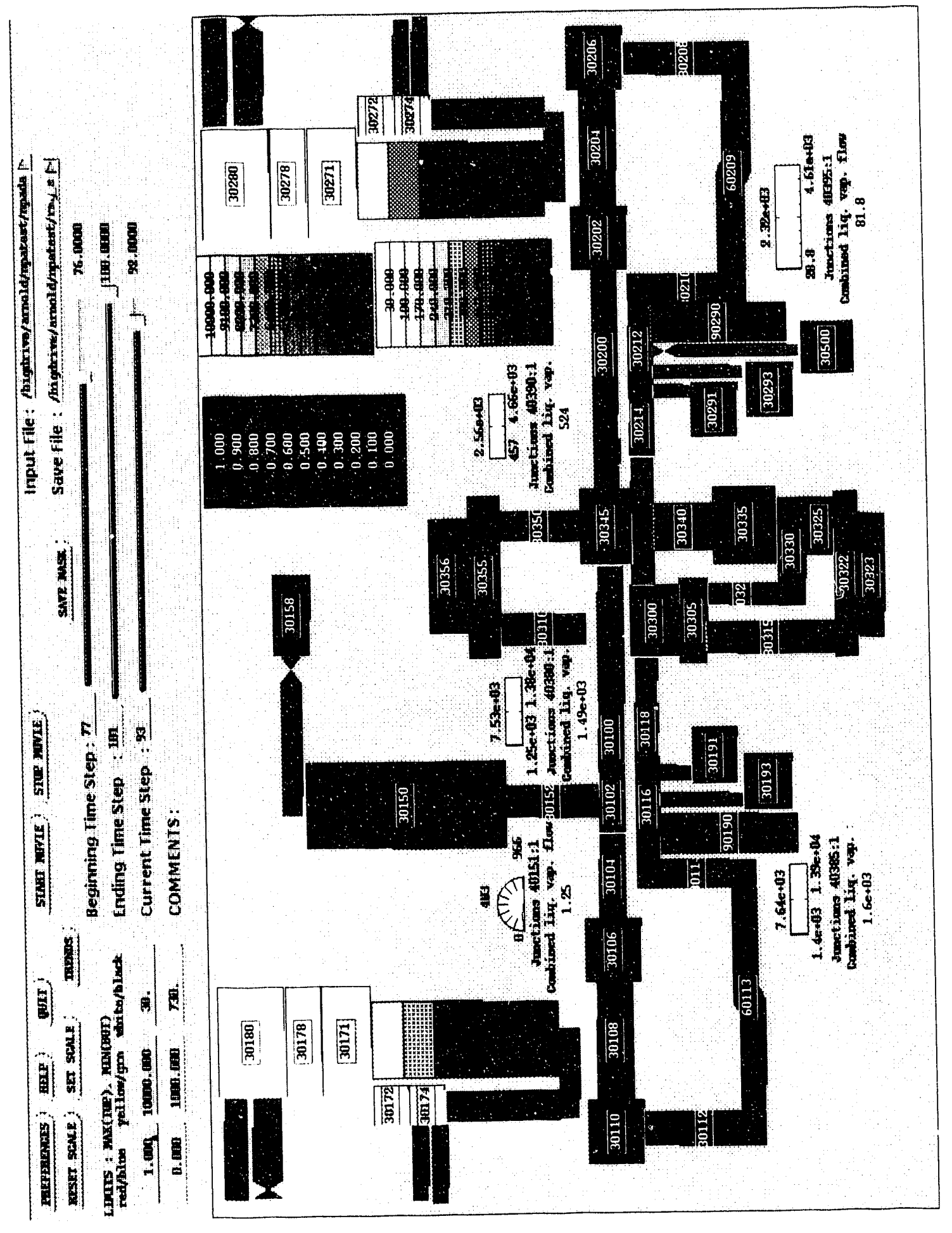




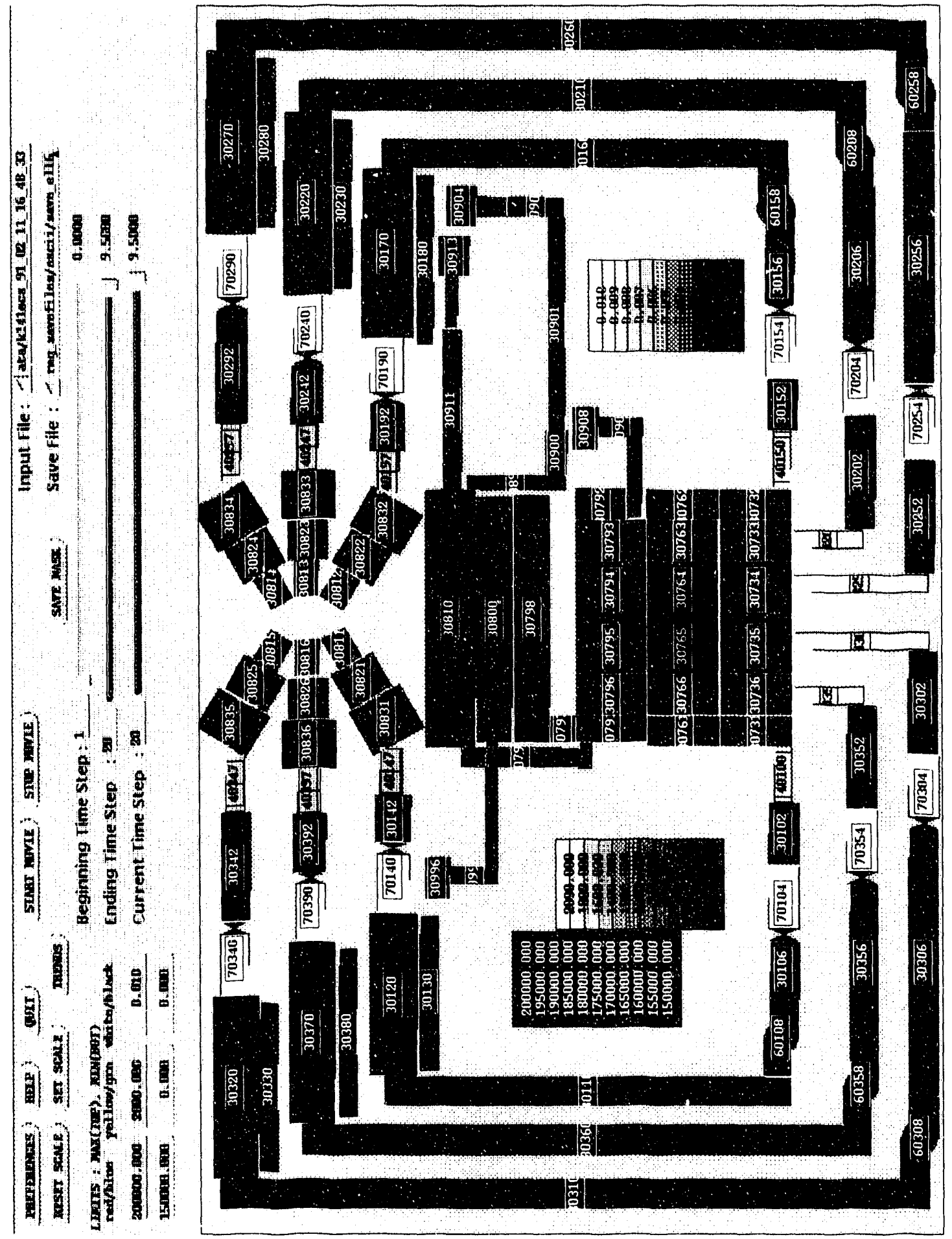




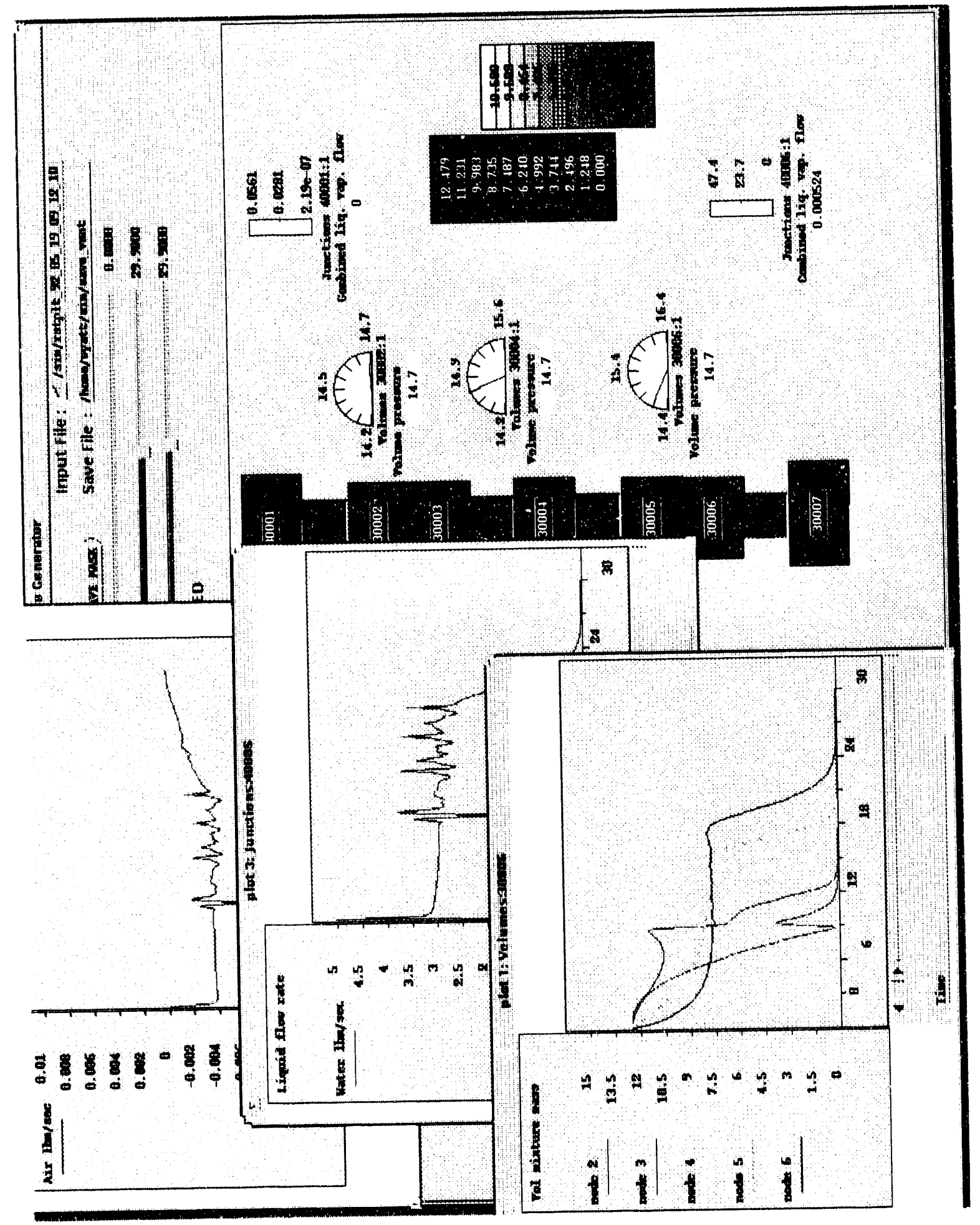




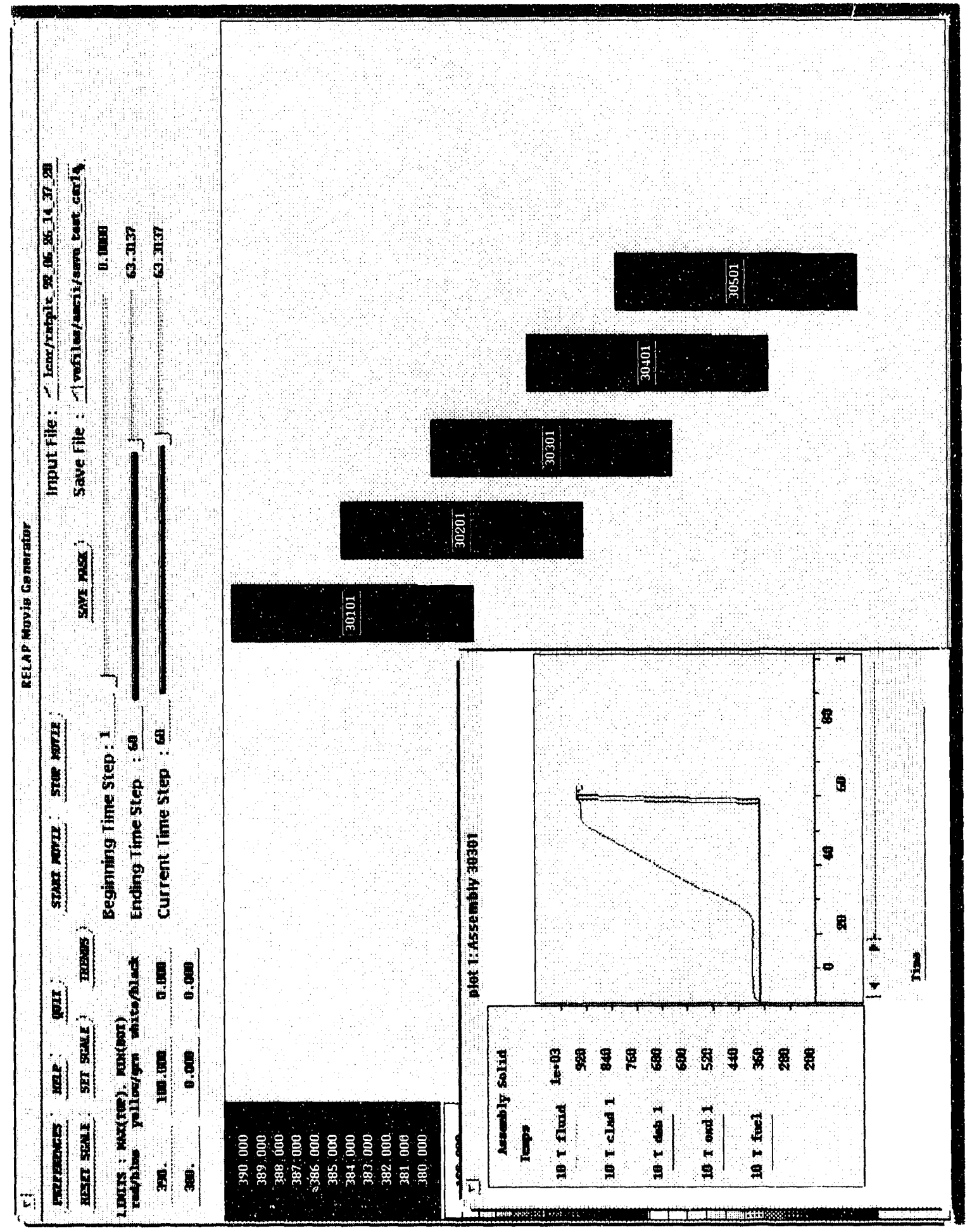



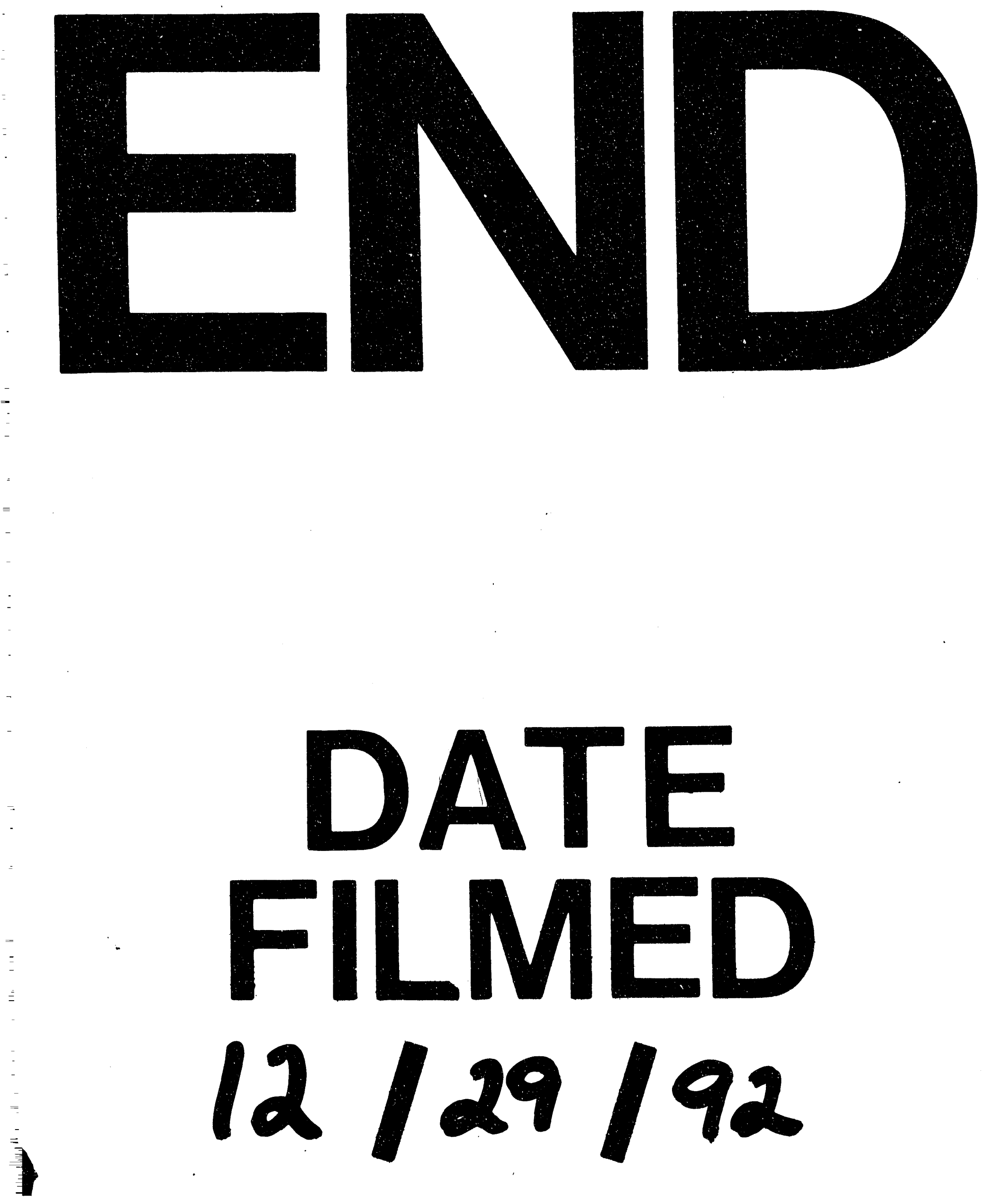
